\title{
Vorsorge des Analkarzinoms
}

Hintergrund

- Anale Dysplasien (anale intraepitheliale Neoplasie, AIN) und Analkarzinome werden durch persistierende HPV-Infektionen verursacht, wobei HPV 16 eine herausragende Rolle spielt

- Weltweit steigende Inzidenzen des Analkarzinoms seit Beginn des Jahrtausends

- Wichtigste Risikofaktoren des Analkarzinoms:

- hohe Anzahl an Sexualpartnern - rezeptiver Analverkehr

- Rauchen und - Immunsuppression (z.B. Medikamente, Organtransplantation, HIV)

- Das höchste Risiko für AIN und Analkarzinome haben HIV-positive Männer, die Sex mit Männern haben (MSM)

- Das Analkarzinom ist wie das Zervixkarzinom durch Vorsorge vermeidbar

- Aufgrund der hohen Prävalenz von AIN und Analkarzinomen bei Hochrisikopatienten wie HIV-positiven MSM existieren entsprechende Leitlinien zur Prävention, Diagnostik und Therapie
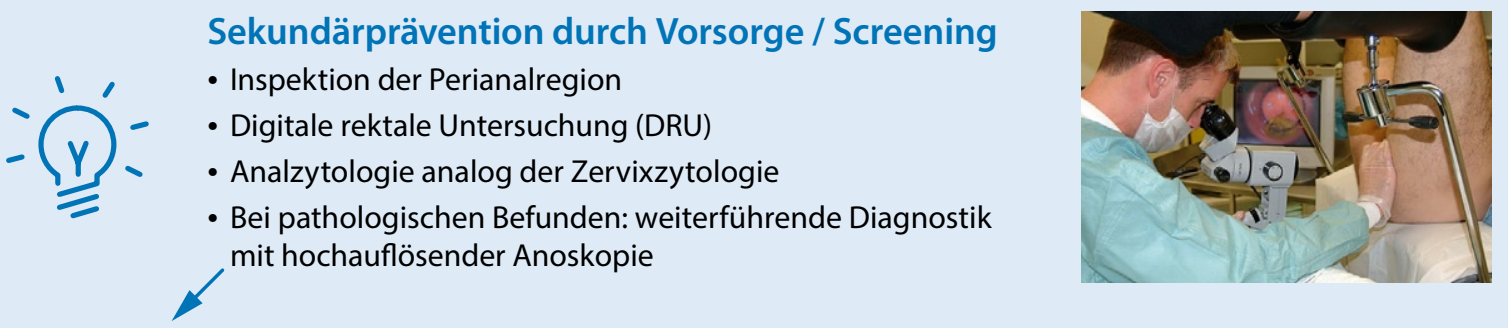

\section{Hochauflösende Anoskopie (HRA) bei pathologischer Zytologie}

- Untersuchung der Analregion (perianal, Analkanal, distales Rektum) in hoher Auflösung mit konventionellem Kolposkop nach Applikation von 5\%iger Essigsäure oder Lugol-Lösung

- Mehr als 75\% aller analer Dysplasien sind an der Linea dentata (Übergangszone) lokalisiert

- Klinisch auffällige Läsionen könnten im Rahmen der HRA biopsiert und/oder behandelt werden
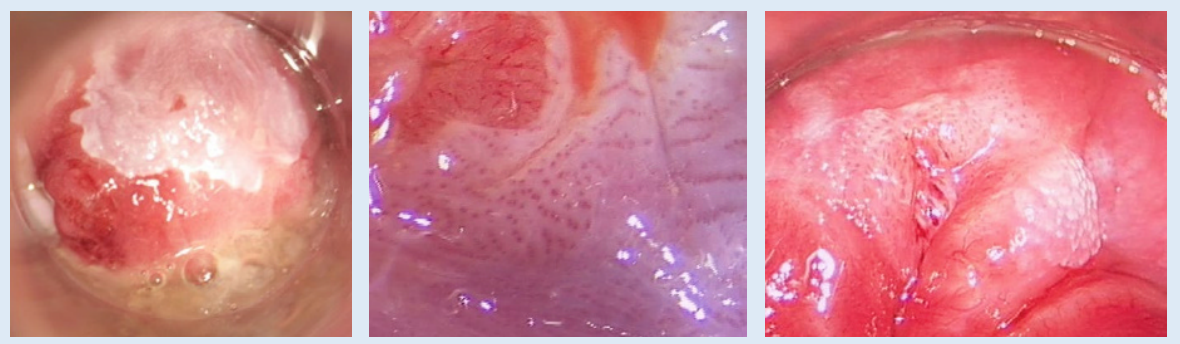

Abb. links: Irregulär konfigurierte Leukoplakie im Bereich der Linea dentata (histologisch hochgradige Dysplasie) mitte: HPV-induzierte "punctuation" rechts: HPV-induziertes "mosaicism" (๔) A. Kreuter)

\section{Primärprävention}

- Prophylaktische HPV-Impfung aller Mädchen und Jungen im Alter von 9 bis 14 Jahren (Nachholimpfung bis zum Ende des 17. Lebensjahres) vor Aufnahme von Sexualkontakten

- Die aktuelle S3-Impfleitlinie der AWMF empfiehlt zudem Impfung von noch nicht HPV-geimpften immunsupprimierten oder immunkompromittierten Menschen bis 26 Jahre

\section{Literatur}

S3-HPV-Impfleitlinie der AWMF (https://www.awmf.org/leitlinien/detail/Il/082-002.html)

S2k-Leitlinie der AWMF zur Prävention, Diagnostik und Therapie von AIN und Analkarzinom

(https://www.awmf.org/leitlinien/detail/ll/055-007.html)

S3-Leitlinie Analkarzinom der AWMF (https://www.awmf.org/uploads/tx_szleitlinien/081-004OLe_ Analkarzinom_Diagnostik-Therapie-Nachsorge-Analkanalkarzinom-Analrandkarzinom_2020-12.pdf)

\section{Springer Medizin}

Lesen Sie mehr: . . . . . . . .

Hautarzt 71: 284-292

https://www.springermedizin.de/link/17715176 